\title{
Quest for Medical Information
}

\author{
Sunil Chaudhry \\ Honorary Medical Director, Bioclinitech Technologies Pvt Ltd, Mumbai \& GPATTutor.com,, India \\ *Corresponding Author: Sunil Chaudhry \\ Email: sunil.r.chaudhry@ gmail.com
}

\begin{abstract}
What is written without effort in general read without pleasure (Samuel Johnson) Scientists communicate the fruits of their labour mostly in writing and for mostly in scientific journals. Conferences and other forms of verbal communication, including the evening news, play important role but written word reaches the widest audience and constitutes the archival message (Kenneth Rothman). The current years have messiah of information on internet
\end{abstract}

Keywords: Health website, drug information, safety of medicinal product.

\section{Introduction}

Health websites contain information items, advices, guides, recommendations, and assessments related to health and related issues and their management. These websites support patients and their families by providing information and can help them to have better patient-physician interaction though detailed information In addition, Internet-based information affects individuals' overall decisions on self-care issues and interaction with health providers Individuals need proper information for involvement in their self-care The internet, however, has not any required standard for qualified information and information in websites is not controlled This means that some websites may publish information with low quality or incorrect content not accord professional guidelines. Thus there is a solution, to browse accredited websites which are authenticated. There is no comprehensive international guideline for health websites design and only few health organizations in some countries such as USA, UK and Australia have developed some guidelines for designing such websites. ${ }^{1}$ Internet usage has rapidly raised and become more common in the past few years. It has a growth of $566.4 \%$ from 2000 until 2012 The qualification of health related websites is not easy to do because it would be an enormous and costly task requiring expert staff in varying fields to monitor too many of health-related websites ${ }^{2}$ The online medical system as a web portal and as a android application installing file. The system is beneficial for both doctor and a patient. This is used in various medical platforms for better physician information ${ }^{3}$

\section{Selected site usage for adequate information}

The net is wide space and browsing of specific sites is required to get valid information. ${ }^{4,5}$

https://www.medicines.org.uk: Up to date, approved and regulated prescribing and patient information for licensed medicines.is available at this site. The electronic medicines compendium (emc) contains up to date, easily accessible information about medicines licensed for use in the UK. emc has more than 14,000 documents, all of which have been checked and approved by either the UK or European government agencies which license medicines. These agencies are the UK Medicines and Healthcare Products Regulatory Agency (MHRA) and the European Medicines Agency (EMA).emc was launched in 1999 and has become an established website, trusted for reliable information about medicines

Utility: It has specified use to prepare prescribing information and Summary of Product Characteristics in accord to global norms. This is required as most of Indian Pharmaceutical sector depends on exports and there is imminent need to register the products both in regulated and unregulated markets.

www.drugs.com: It is the most popular, comprehensive and up-to-date source of drug information online. Providing free, peer-reviewed, accurate and independent data on more than 24,000 prescription drugs, over-the-counter medicines \& 
natural products. Most of information in the prescribing leaflets can also be taken from this site. This has also android operating application, which is common with all relevant websites.

https://www.bnf.org/products/bnf-online/: For the British National Formulary Information on drugs is drawn from the manufacturers' product literature, medical and pharmaceutical literature, UK health departments, regulatory authorities, and professional bodies. The BNF also takes account of authoritative national guidelines and emerging safety concerns. In addition, the editorial team receives advice on all therapeutic areas from expert clinicians Advice is constructed from clinical literature and reflects, as far as possible, an evaluation of the evidence from BNF provides prescribers, pharmacists, and other healthcare professionals with independent up- to-date information about the use of medicines and includes key information on the selection, prescribing, dispensing and administration of medicines. The BNF Publications (often referred to collectively as the BNF) are three key titles - the British National Formulary (BNF), the British National Formulary for Children (BNFC) and the Nurse Prescribers' Formulary (NPF).

For more than 65 years, Drug Facts and Comparisons has been an industry-leading source for extensive drug information, published under proprietary editorial processes designed to keep information as unbiased as possible. Facts \& Comparisons e Answers supports pharmacists and other professionals with an updated, crystal-clear user interface featuring common sense navigation and expanded content and tools to make accessing key drug knowledge even easier.

This is a useful paid resource.

\section{https://www.wolterskluwercdi.com/facts- comparisons-online/}

\section{AHFS)American Hospital Formulary Service:}

Trusted by pharmacists and other healthcare professionals for over 60 years, $A H F S \circledR D I^{\mathrm{TM}}$ is the most comprehensive evidence-based source of drug information complete with therapeutic guidelines and off-label uses and includes electronic monographs. To access, you will be required to login with a username and password, which can be found in the preface of each annual edition of AHFS DI. This is also paid resource.

\section{https://www.ahfsdruginformation.com/ahfs-drug- information/}

https://www.fda.gov/home: This is the official site for US FDA. It deals with laws, drug and device approvals. https://www.accessdata.fda.gov/scripts/cder/daf/ takes to the profile of US approved drugs in details.

http://www.cdc.gov Center for disease control is a part of the U.S. Department of Health and Human Services, deals with preventing and controlling disease, injury and disability and its website ably reflects this mission. Health Information is clearly illustrated.

\section{https://cdsco.gov.in/opencms/opencms/en/Home:}

This is the official site for the regulatory bodies in India. Under the Drugs and Cosmetics Act, CDSCO (Central Drugs Standard Control Organization) is responsible for approval of Drugs, Conduct of Clinical Trials, laying down the standards for Drugs, control over the quality of imported Drugs in the country and coordination of the activities of State Drug Control Organizations by providing expert advice with a view of bring about the uniformity in the enforcement of the Drugs and Cosmetics Act.

http://ipc.gov.in/PvPI/pv_home.html: From 1 January 2005, WHO-sponsored and World Bankfunded National Pharmacovigilance Program for India was made operational.

The Pharmacovigilance Programme of India (PvPI) was initiated by the Government of India in July 2010 with AIIMS, New Delhi as for monitoring ADR in the country for safe-guarding public health by assuring the safety of medicinal products. Before registration and marketing of medicine in the country, its safety and efficacy experience is based primarily on the use of the medicine in clinical trials. These trials also detect adverse reactions but some of the important reactions, such as those, which take a long time to develop, or those, which occur rarely, may not be detected in the clinical trials. medicines are used in clinical trials do not necessarily reflect the way they will be used in practice. The Medical Colleges and hospitals are the corner stone of the PvPI. They act as AMCs which are responsible for collecting the Individual Case Safety Reports (ICSRs) and performing the follow up to obtain necessary supplementary detailed information for scientific evaluation of the cases. The main aim of 
Pharmaceutical industry is to have robust in house sysyem to report ADR (adverse drug reactions).

\section{Specified site usage for adequate information}

Clinical care Options: educational programs are available completely free of charge. Therapeutic areas include diabetes, Hepatology, Cariology and Oncology. Slidesets, discussions on scientific text, Full text articles can be downloaded. Online symposia can be attended. https://www.clinicaloptions.com/

General Medical websites: These provide relevant information in various therapeutic areas

www.4physicians.com

www.cancerguide.org

www.cmesearch.com

www.mentalhealth.com

www.medconsult.com

www.medscape,com

Physicians desk reference: The Physicians' Desk Reference (PDR) is widely used source of drug information by American physicians and patients, The Physicians' Desk Reference (PDR) is a commercially published compilation of manufacturers' prescribing information (package insert) on prescription drugs, updated annually, includes information on all drugs that are approved for use by the FDA, https://www.pdr.net/about-pdrnetwork/. PDR provides event-driven and clinically relevant healthcare messaging through its patented process that improves patient compliance and outcomes, while preserving privacy. This network is made up of e-prescribing, electronic medical record (EMR), and electronic health record (EHR) applications.

www.webMD,com The leading source for trustworthy and timely health and medical news and information. It provides credible health information, supportive community, and educational services.

\section{Important Journal Websites:}

Journal of American Medical Association (JAMA) www.jama.com. JAMA Network Open publishes original research and commentary on clinical care, health policy, and global health.
British Medical Journal (BMJ) - www.bmj.com: The BMJ is a weekly peer-reviewed medical journal. It is one of the world's oldest general medical journals.

https://www.journals.elsevier.com/the-lancet/:

The Lancet is the world's leading independent general medical journal. The journal's coverage is international in focus and extends to all aspects of human health.

The Lancet publishes the original primary research and review articles of the highest standard. The Lancet is stringently edited and peer-reviewed.

Trends in Pharmacological Sciences is the leading monthly review journal in pharmacology and toxicology (Impact factor 10.148). Every issue of Trends in Pharmacology Sciences contains succinct articles on the most exciting recent developments in pharmacology researchhttps://www.sciencedirect.com/journal/trends-inpharmacological-sciences

Annals of Internal Medicine's mission is to promote excellence in the clinical practice of internal medicine, to help physicians be well-informed citizens of the medical community and society, and to publish information that helps to advance the health of people worldwide. https://www.acpjournals.org/

https://journals.sagepub.com/coronavirus: This is specially dedicated to Covid infection. It provides epidemiology, prevalence, diagnosis, treatment of Infection and the future therapies which are being evaluated.

All the above require annual subscription

\section{Some Important Indian Journals are: ${ }^{4}$ :}

Journal of Association of Physicians of India (JAPI)https://www.japi.org/

RSSDI (Research Society for the Study of Diabetes in India) Currently, life members are represented from 21 Indian States and Union Territories www.rssdi.in. The objective of society is to encourage, educate, update and train registered medical practitioners, dietitians, qualified nurses and other appropriately qualified paramedical personnel in the field of Diabetes and expand knowledge on health care delivery through organization of lectures, continuing medical education programs (CME), seminars, discussions, conferences, update sessions, workshops, training camps., since India is indeed diabetes capitol of the world. 
Indian Medical Gazette This is published monthly and journal has prestige of being more than 100 years old, mentioned in Index Copernicus Publishers are in Kolkata and this is widely circulated in eastern segment of India. It has clinical presentations and original research articles from Academia and Pharmaceutical Industry. Published monthly. Online issues of are available. The archives are available on https://www.ncbi.nlm.nih.gov/pmc/journals/2470/ and the recent on https://medind.nic.in/ice/icem.shtml

\section{Pharmaceutical search engines}

IFPMA Clinical Trials Portal: Developed in conjunction with information technology leader IBM, this was the first internet search engine constructed specifically to link to on-line information made available by the innovative pharmaceutical industry about clinical trials worldwide.

LegitScript: According to the site, this resource is a source of information for patients, Internet users, physicians, businesses and other third parties who need to know if an Internet pharmacy is acting in accordance with the law and accepted standards of ethics and safety.

MediLexicon: MediLexicon has the world's largest online database of pharmaceutical and medical abbreviations - over 230,000 and growing. MediLexicon contains searches, information, news and resources for medical, pharmaceutical and healthcare professional.

Omni Medical Search: This search engine offers search options, a reference desk, information about conditions and diseases and a local directory - all gathered from 25 databases, including authoritative medical search engines, image libraries and the latest health and medical news.

PogoFrog provides a medical research engine for physicians who use the Internet regularly to research varied healthcare subjects.

RXCut Pharmacy Search Engine: Use this mashup of Google Maps and a database to find a pharmacy located near you.

\section{Pharmaceutical Directories}

Bio Pharma Link: Initially BioPharmaLink provided an easy tool to retrieve information about companies and institutions that contribute directly to the development, manufacturing, licensing and distribution of medicines and therapies for the prevention and treatment of human illness.

PharmWeb: Since its launch in 1994 PharmWeb has developed into the premier online community of pharmacy, pharmaceutical and healthcare-related professionals with over 40,000 self-registered users.

RxList: RxList is an online medical resource dedicated to offering detailed and current pharmaceutical information on brand and generic drugs. RxList is Owned and Operated by WebMD and part of the WebMD network.

\section{Portals for Health Profesionals}

Practo.com - Online doctors appointment service that cover the most regions of India in fact highest number of cities \& towns i.e. 58 cities and other similar online services in India are not even close to it.

DocSuggest - A doctor search online service for Bangalore, Delhi/NCR, Hyderabad and Mumbai. DocSuggest also has Android app for mobiles to book appointment via mobile.

NamasteDoc - A free doctor search and fix appointment, one can search doctors by name, by hospital or by specialty, at moment the service is available in Delhi/NCR area, Mumbai and Jaipur.

\section{E medicine and Portal Developing companies}

There are many such corporates which help doctors as well patients to haver optimal information about the product. Few of such suppliers are Bioclinitech technologies Private limited based at Mumbai www.bioclinitech.com, other is Qmed knowledge foundation - https://www.qmed.ngo/.

\section{Conclusion}

Quality factor is particularly important because misinformation can lead to inappropriate patient safety which can be of concern The internet is vast network which has changed the scope of medical information in terms of providing rapid update, Medical Research, teaching, clinical practice have been influenced by internet and in current era Video conferencing, Webtelecasts, Podocasts have dominated the conservative methods of teaching. The importance of a website for marketing extends to every aspect of digital 
marketing strategy. As the backbone of online presence, every type of communication, piece of content, or advertisement that is put online will drive the consumer back to website. As such, it's important that website gives consumers a clear idea of what your brand is about and what types of products or services are offered.

\section{Source of Funding}

None.

\section{Conflict of Interest}

None.

\section{References}

1. Haghi SV, Moghaddasi H, Rabiei R, Asadi F, Health websites visual structure: the necessity of developing a comprehensive design guideline. J Paramed Sci Autumn 2017;8(4).

2. Rahmatizadeh $\mathrm{S}$, Evaluating the trustworthiness of consumeroriented health websites on diabetes Library Philosophy and Practice, Spring 2018

3. Nandagawali A, Sute K. Int Res J Eng Technol 2018;99-102.

4. Website specifics are taken from site.

5. General Health, Health Websites You Can Trust 2013

How to cite: Chaudhry S. Quest for Medical Information. J Pharm Biolog Sci 2020;8(1):38-42. 